\section{ECCOMAS}

\section{Proceedia}

COMPDYN 2021

$8^{\text {th }}$ ECCOMAS Thematic Conference on Computational Methods in Structural Dynamics and Earthquake Engineering M. Papadrakakis, M. Fragiadakis (eds.) Streamed from Athens, Greece, 28 - 30 June 2021

\title{
SHAKING TABLE TEST ON THE EFFECTS OF SHEAR WALLS FOR LONG-SPAN KOREAN TRADITIONAL TIMBER STRUCTURE
}

\author{
Yeong-Min. Kim ${ }^{1}$ \\ ${ }^{1}$ Professor, College of Architecture, Myongji University \\ 116 Myongji-ro, Cheoin-gu, Yongin, Gyeonggi-do, 17058, Republic of Korea \\ e-mail: ymkim@mju.ac.kr
}

\begin{abstract}
In this research, the dynamic characteristics and effects of shear walls in lateral stiffness of long-span Hanok have been studied by shaking table test. The 1/20 scale experimental model for the long-span test-bed Hanok has been built for shaking table test. The shaking table test was done on two cases, that is, full or no shear wall. The shaking table test was done on a 1/20 scale experimental model for the previous two cases. The experiment was done sequentially, first for full shear wall model, and then no shear wall model. The shaking table was actuated sequentially by four types of input gain, that is, from random gain 1 to random gain 4 with increasing scenario. The maximum displacement of experimental model on its roof top was measured for both full and no shear wall cases for four random gains. Full shear wall case showed much less displacement for all random gains compared to the no shear wall case. The average displacement reduction ratio for four random gains is $64.4 \%$, which shows the significant effect of shear wall in lateral load resisting capability. The natural vibration frequency of full shear wall is $11.28 \mathrm{~Hz}$ compared to the no shear wall of $5.5 \mathrm{~Hz}$, which shows stiffness is about 4 times.
\end{abstract}

Keywords: Long-span Hanok, Shaking Table Test, Shear Wall, Lateral Stiffness.

ISSN:2623-3347 (C) 2021 The Authors. Published by Eccomas Proceedia. Peer-review under responsibility of the organizing committee of COMPDYN 2021. doi: $10.7712 / 120121.8783 .19173$ 


\section{INTRODUCTION}

The Korean traditional timber structure, especially used as residential is called Hanok. Hanok has history of more than two thousand years. The structure of Hanok as shown in Fig. 1(a) is characterized as a post and beam structure. The vertical load is supported mainly by post and beam as shown in Fig. 1(b), and the lateral load is supported mainly by walls incorporated with peripheral timber frame. In a very rare case, truss is used as lateral load resisting system as shown in Fig. 1(c).

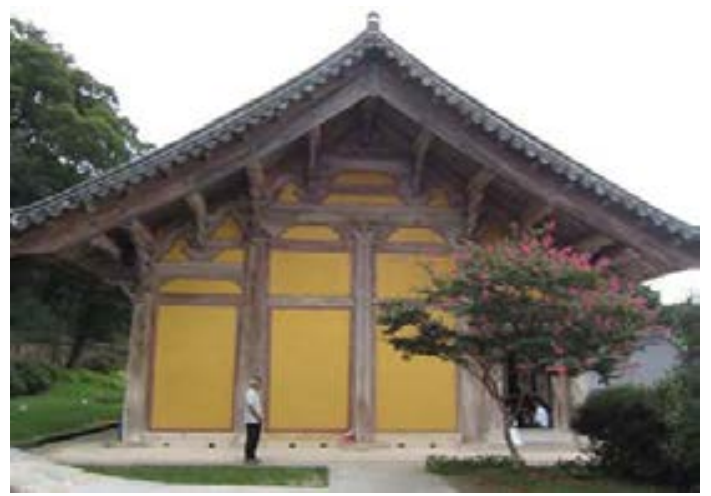

(a) Korean Traditional Timber Structure

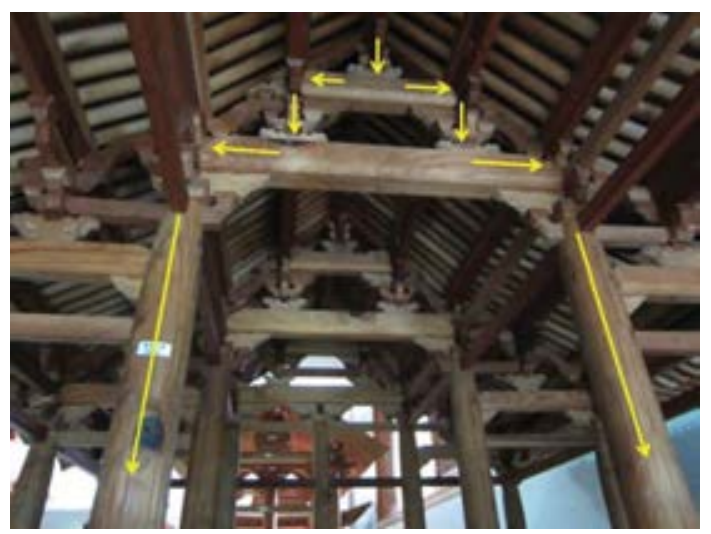

(b) Load paths of through post and beam in Hanok

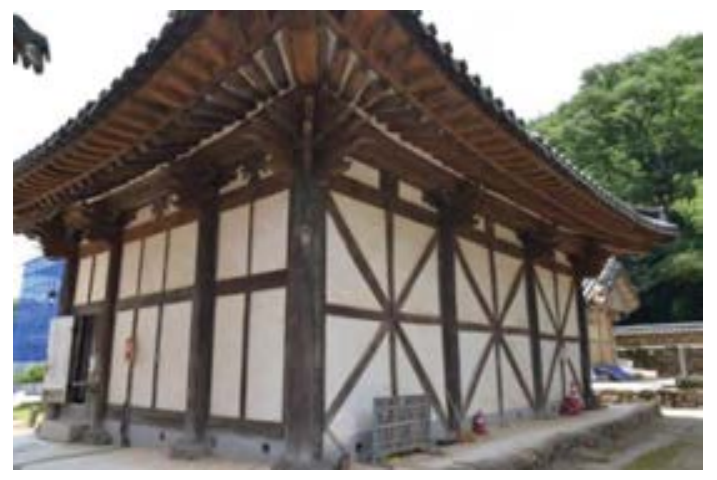

(c) Trussed wall used as a lateral load resisting system in Hanok

Figure 1: Korean traditional timber structure and its load paths

The main characteristic of Hanok is in its joints. The joint of Hanok is mostly mortise and tenon joint of only wood as shown in Fig. 2. It rarely uses steel connector or steel nails. The 
heavy roof weight of Hanok helps the joint have somewhat rotational rigidity against lateral load. Generally, the span of traditional Hanok between columns is about 2.4 4.8 meters. This short span does not matter as a residential use. Nowadays, long span, which is about 10 20 meters, is required to accommodate various modern life style of people and to enlarge the use of Hanok as a public usage. As the span is longer various problems should be solved in structural point of view.

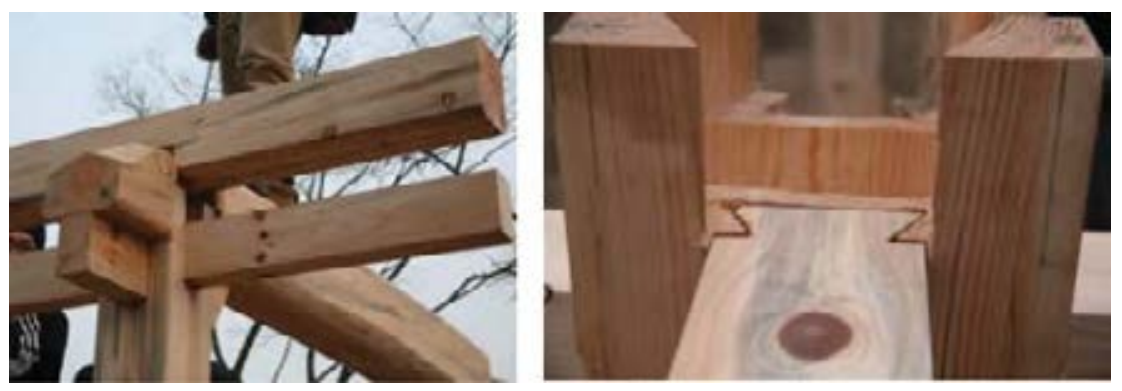

Figure 2: Traditional mortise and tenon joint of Hanok

As the span of Hanok becomes longer, new load carrying paths and new joint types should be carefully planned and designed to support increased load and unfamiliar large inner space. Timber structure in East Asia and the West has much in common in their skeleton and construction method. So, various researches on the timber structures have been carried out extensively around the world. Seo et al. [1] studied the structural characteristics of wooden frames with tenon joints under lateral static and cyclic load, Han et al. [2] studied mechanical performance of tenon joints to enhance traditional wooden house, Kang et al. [3] studied the static performance of mortise and tenon joint in Chinese traditional timber structure, Lee et al. [4], [5] studied both the longitudinal and transversal load carrying capacity of Korean traditional timber structure, and Kim et al. [6] evaluated rotational stiffness of steel joints used in a newstyled Hanok by static experiment on a 1/4 scale model.

Fang et al. [7] performed dynamic test on traditional Chinese timber structure and verified its structural characteristics, Hwang et al. [8] performed shaking table test on Korean traditional timber structure and showed the variation of natural frequency according to vibration amplitude, and Lee et al. [9] compared dynamic characteristics of both traditional and newstyled Hanok according to excitation amplitude. Ozsev et al. [10] conducted small scale hands-on experiments on a model wooden frame structure under dynamic effects.

As a design aid to the Korean traditional timber structures, section tables and structural design software for the design of main structural members of Hanok has been developed [11],[12],[13],[14] and these design tools were used in making Korean design standard on Hanok. Recently, evaluation tool on the torsional irregularity of Hanok has been developed to aid seismic design of Hanok [15].

In this study, the dynamic characteristics of long-span Hanok and the effects of shear walls in lateral stiffness have been studied by shaking table test and the results are analyzed.

\section{EXPERIMENTAL MODEL FOR SHAKING TABLE TEST}

The long-span test-bed Hanok with its transversal span of 14.4meter and longitudinal span of 25.2meter has been designed as shown in Fig. 3. This long-span test-bed Hanok is scheduled to be built in Yongin, Korea, 2021. The 1/20 scale experimental model for this long-span test-bed Hanok has been built for shaking table test as shown in Fig. 4(a). The vertical load 
was imposed on the roof and floor of the experimental model with steel plate as shown in Fig. 4(b). The total weight is $87.24 \mathrm{~kg}$.

The shaking table test was done on two cases, that is, Case A and Case B as shown in Table 1. Case A has full shear wall, that is, no opening, whereas, Case B has no shear wall, that is, full opening. Fig. 5(a) shows the location of shear wall in plan, and Fig. 5(b) and Fig. 5(c) show the front and rear view of test model of Case A.

The motor of shaking table is operated by real-time displacement control method using Labview program of NI corporation. The velocity, corresponding to input acceleration was numerically integrated and this was used as the input signal of motor. Four accelerometers were used to measure both $\mathrm{X}$ and $\mathrm{Y}$ directional movement. The sampling rate for data is $3200 \mathrm{~Hz}$. The relative displacement of the model compared to the base was measured by laser displacement equipment by measuring both the roof and base displacement of the model.

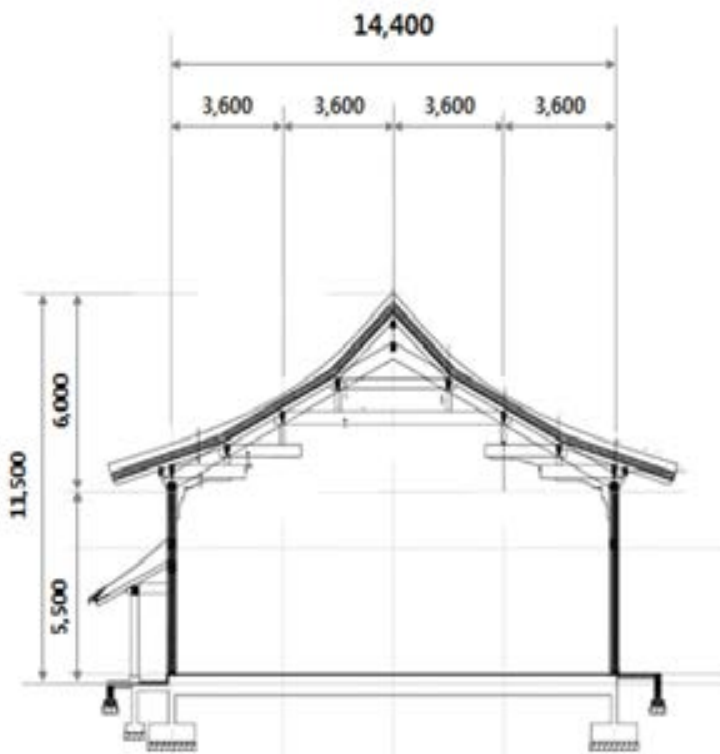

(a) Section of low-rise part

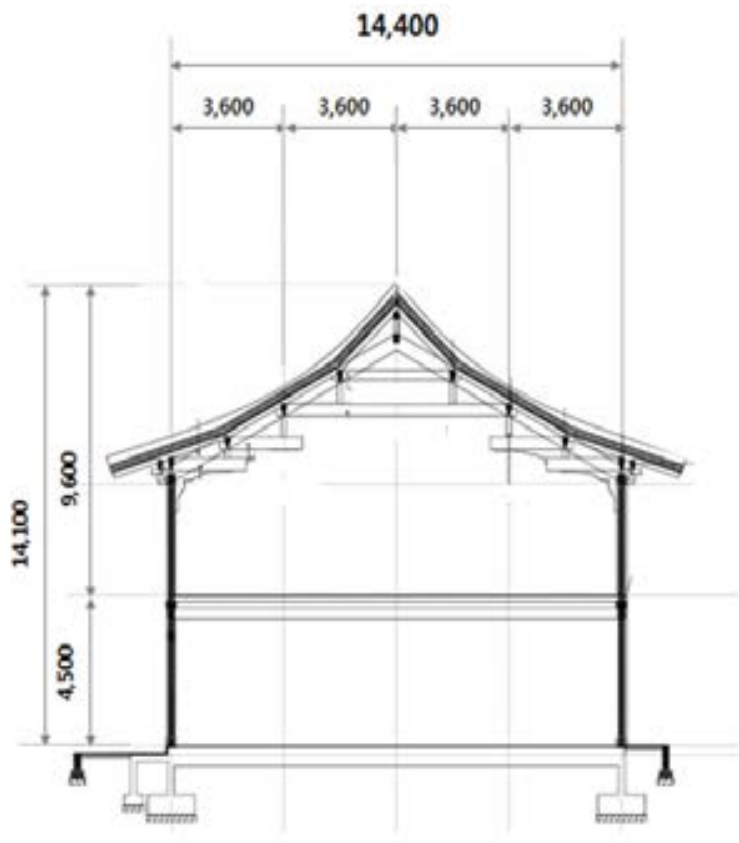

(b) Section of high-rise part

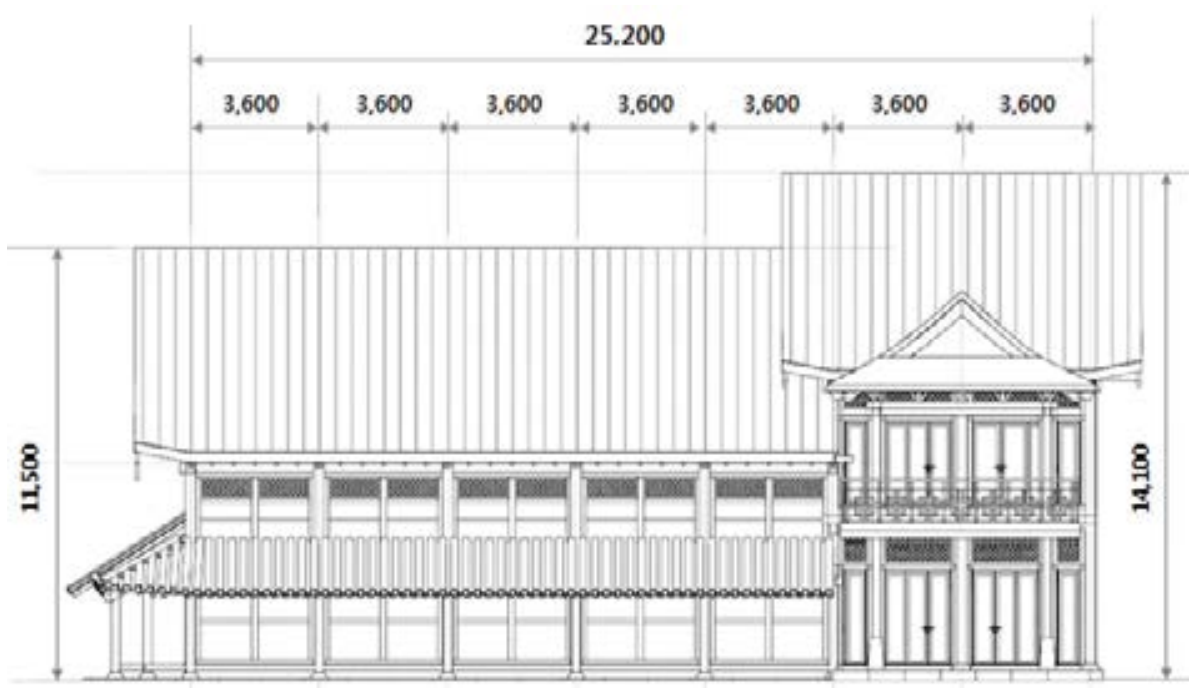

(c) Elevation 

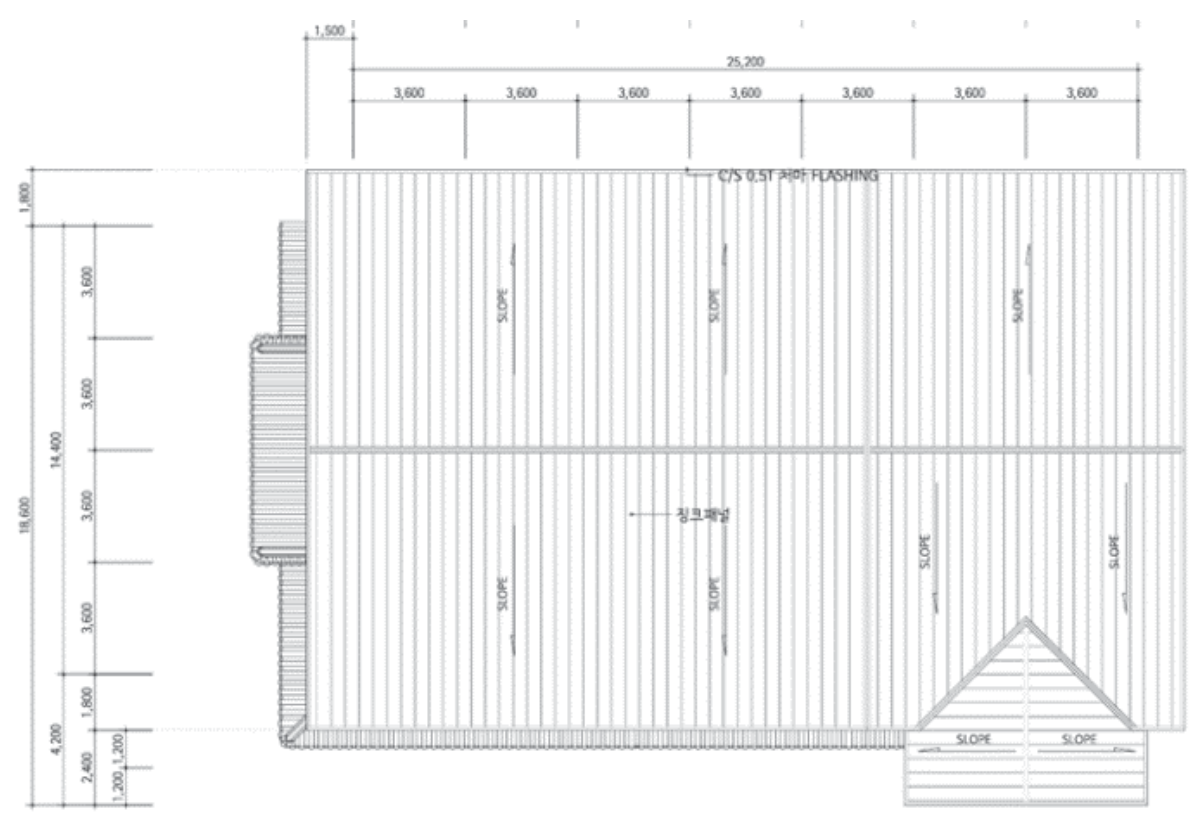

(d) Roof

Figure 3: Section, elevation and roof plan of actual building

\begin{tabular}{lll}
\hline Model Case & Shear walls & Opening ratio \\
\hline Case A & Full shear walls (No opening) & $0 \%$ \\
Case B & No shear walls (Full opening) & $100 \%$ \\
\hline
\end{tabular}

Table 1: Opening ratio of each cases.

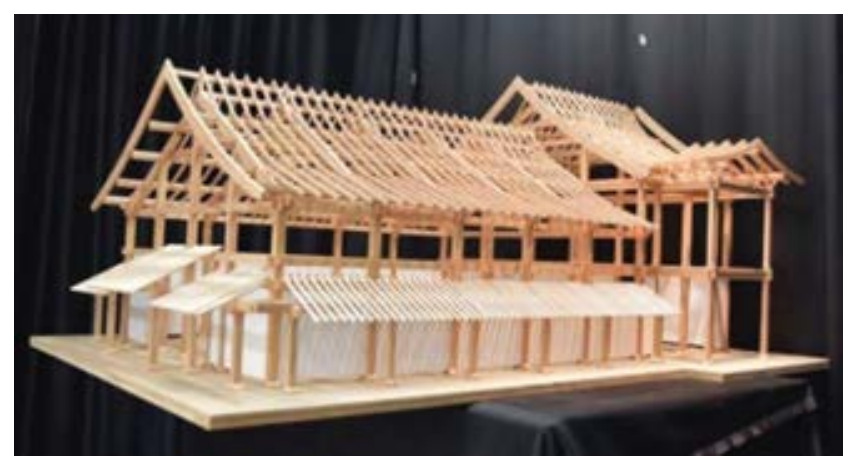

(a) $1 / 20$ scale experimental model for shaking table test

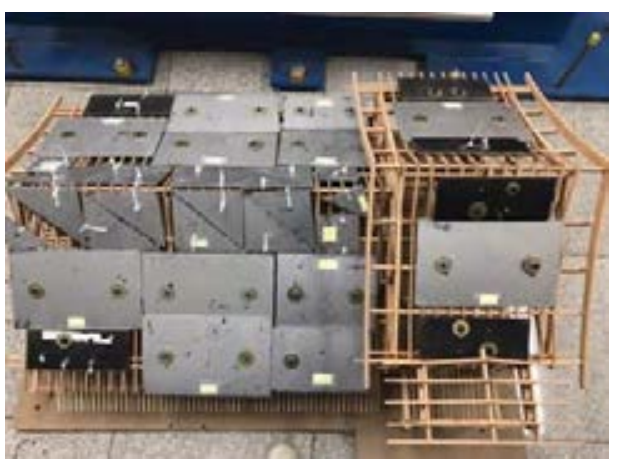

(b) Imposition of vertical load by steel plate

Figure 4: . 1/20 scale experimental model and imposition of vertical load

\section{SHAKING TABLE TEST ON EXPERIMENTAL MODEL}

The shaking table is one-directional as shown in Fig. 6. The experiment was done sequentially. First, shaking table experiment was done for Case A with full shear wall as shown in Fig. 7(a), and then shear wall was removed and the same shaking table experiment was done, which is for Case B as shown in Fig. 7(b). There are four types of input gain to the shaking 
table as shown in Fig. 8, that is, from random gain 1 to random gain 4 with sequentially increasing scenario.
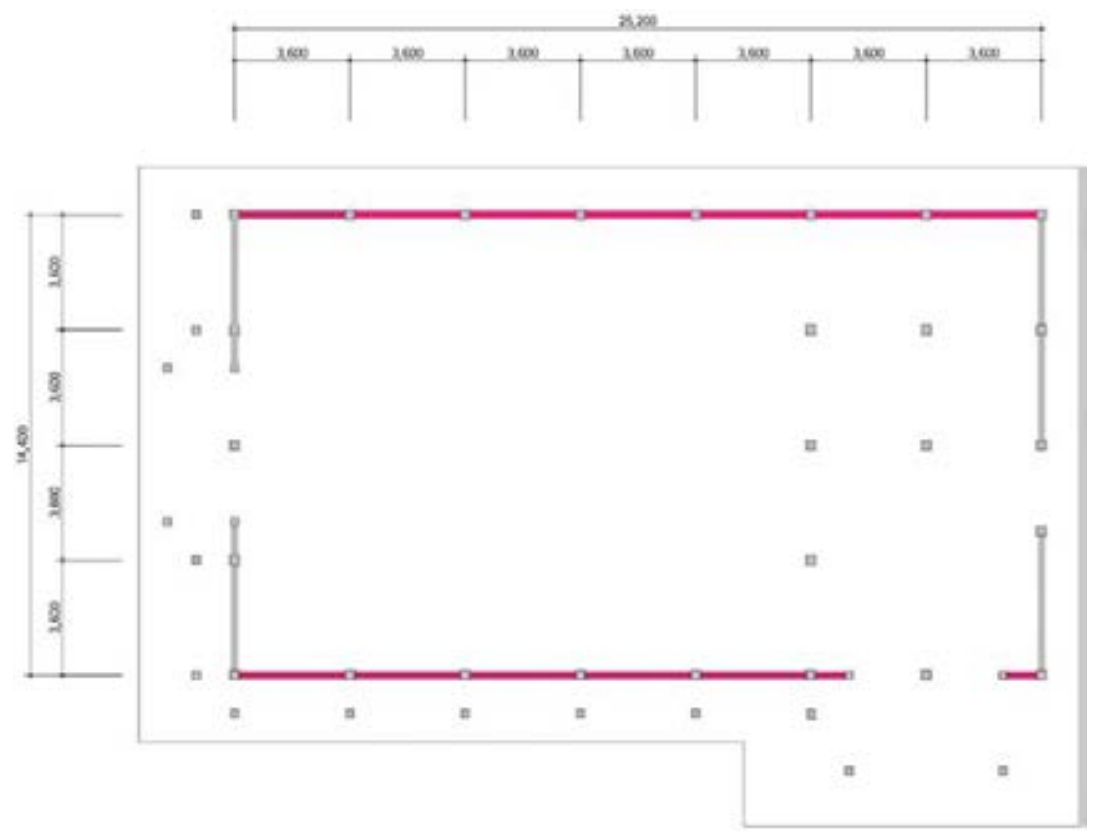

(a) Location of shear wall in plan

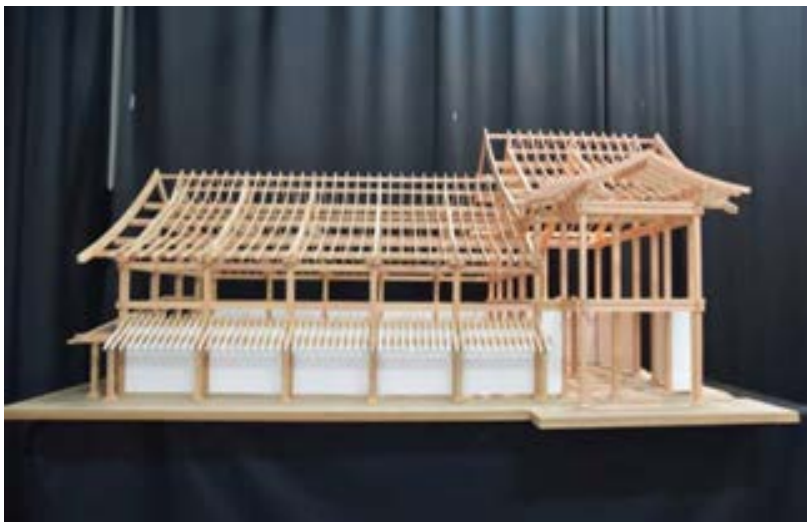

(b) Front view and location of shear wall

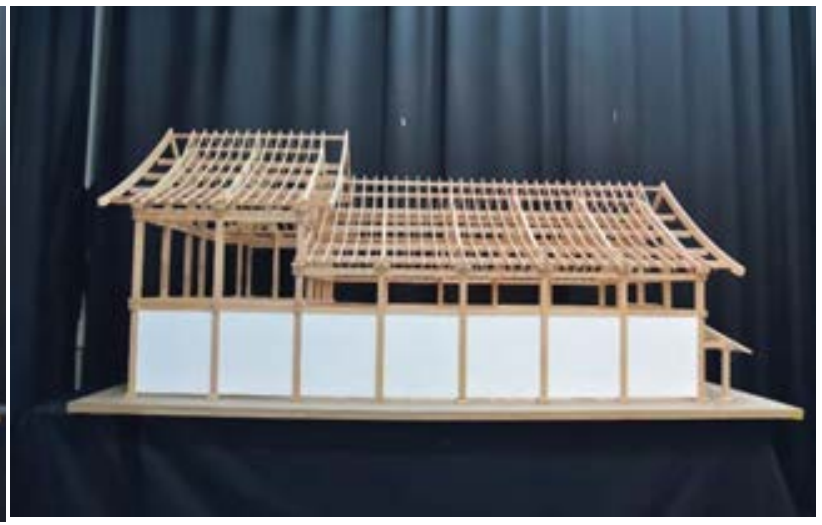

(c) Rear view and location of shear wall

Figure 5: Location of shear wall in plan and 1/20 scale test model

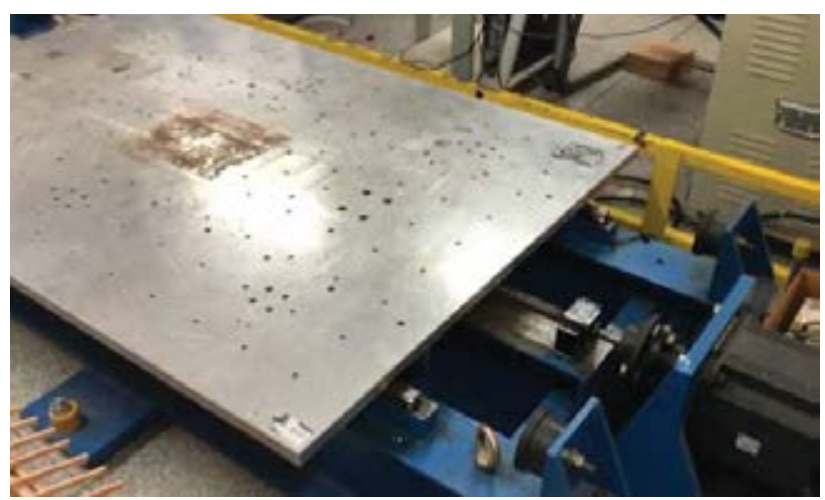

Figure 6: Shaking Table 


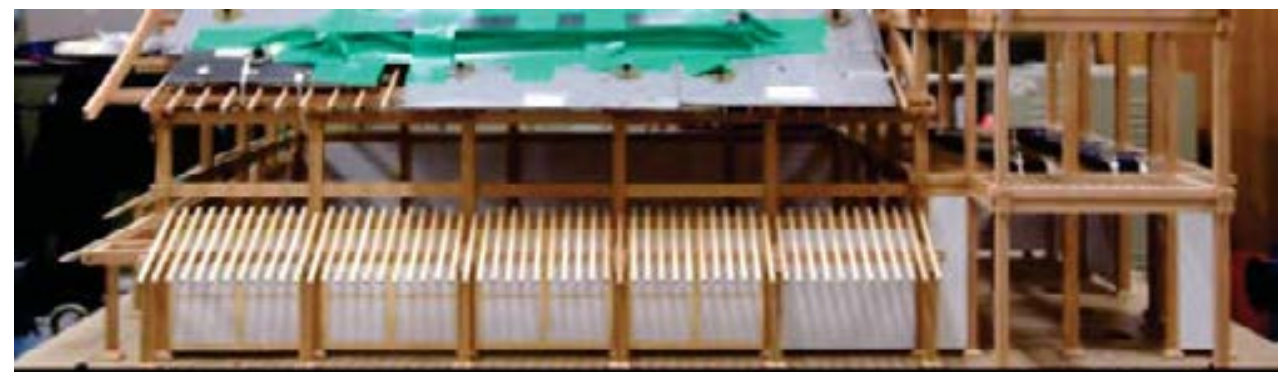

(a) Case A : full shear wall with no opening

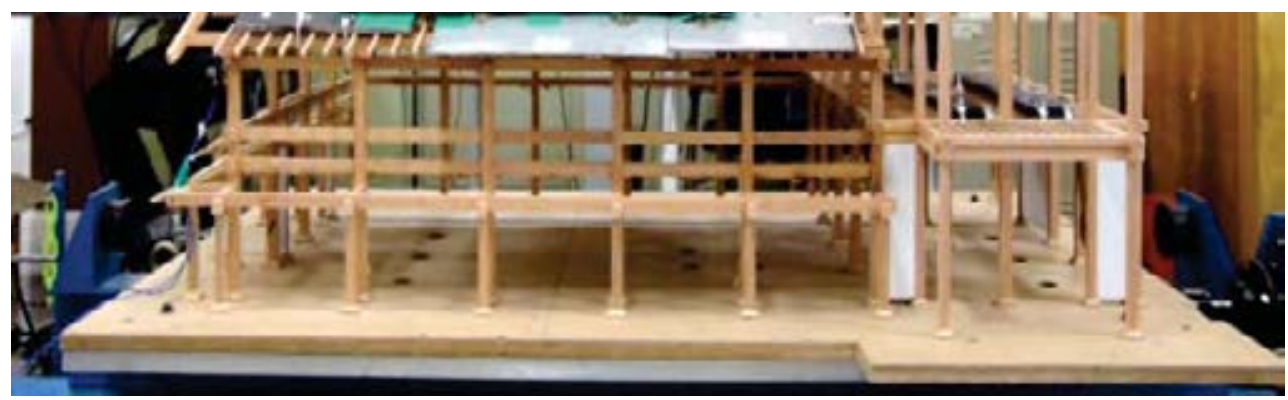

(b) Case B : no shear wall with full opening

Figure 7: Two experimental models, Case A and Case B

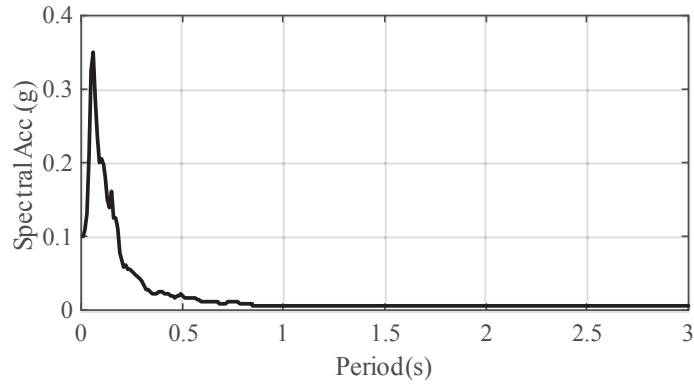

(a) Random Gain 1

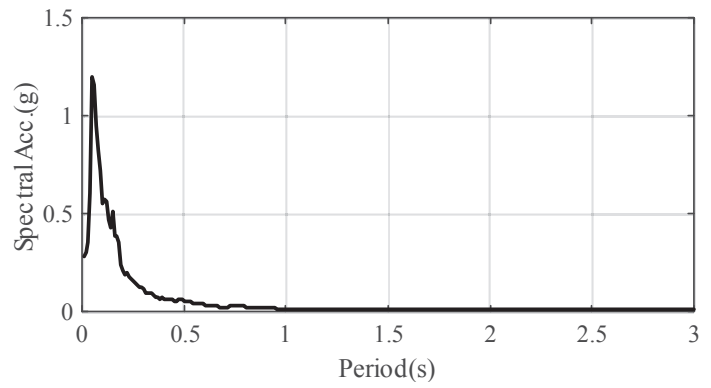

(c) Random Gain 3

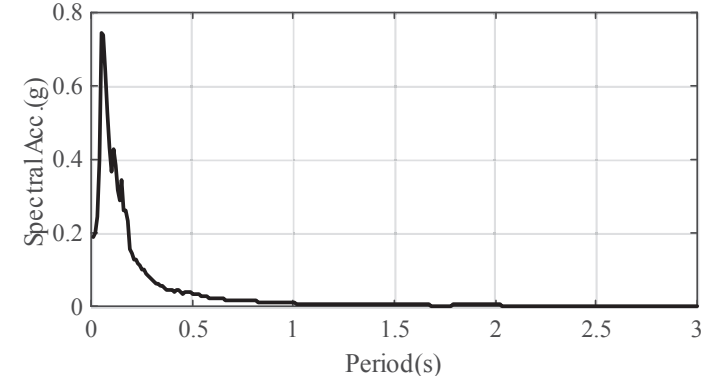

(b) Random Gain 2

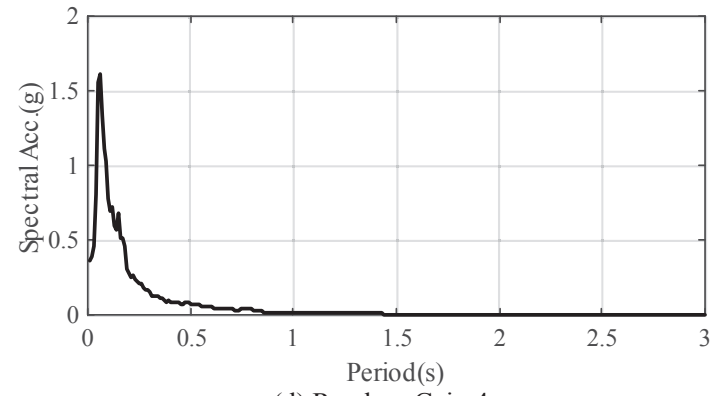

(d) Random Gain 4

Figure 8: Response spectrum of four types of random gain

\section{RESULTS OF SHAKING TABLE TEST}

The maximum displacement of experimental model on its roof top was measured for Case A and Case B for each random gain. The results are shown in Table 2. Compared to Case B, which has no shear wall, Case A showed much less displacement for all random gains. The 
average displacement reduction ratio for four random gains is $64.4 \%$. Here we can deduce that, the shear wall shows significant effect in lateral load resisting capability.

The natural vibration frequency of Case $\mathrm{A}$ is $11.28 \mathrm{~Hz}$ compared to the Case $\mathrm{B}$ of $5.5 \mathrm{~Hz}$. As the vibration frequency is about two times larger, we can deduce that the stiffness is about 4 times larger. Here we only compared the maximum displacement and natural vibration frequency only for preliminary test. The other dynamic characteristics including torsional effect are scheduled to be studied in the coming paper.

\begin{tabular}{llll}
\hline \multirow{2}{*}{ Input load } & \multicolumn{2}{l}{ Maximum displacement $(\mathrm{mm})$} & \\
\cline { 2 - 3 } & $\begin{array}{l}\text { Case A } \\
\text { (No opening) }\end{array}$ & $\begin{array}{l}\text { Case B } \\
\text { (Full opening) }\end{array}$ & \\
\hline Ran. Gain 1 & 0.44 & 1.43 & 69.2 \\
Ran. Gain 2 & 0.80 & 2.61 & 69.3 \\
Ran. Gain 3 & 1.25 & 3.22 & 61.2 \\
Ran. Gain 4 & 1.56 & 3.71 & 58.0 \\
\hline
\end{tabular}

Table 2: Displacement Reduction Ratio According to Shear Wall

\section{CONCLUSIONS}

In this research, the dynamic characteristics of long-span Hanok and the effects of shear walls in lateral stiffness have been studied by shaking table test and the results are analyzed. The 1/20 scale experimental model for the long-span test-bed Hanok has been built for shaking table test. The shaking table test was done on two cases, that is, full or no shear wall. The shaking table test was done on a 1/20 scale experimental model for the previous two cases.

The experiment was done sequentially, first for full shear wall model, and then no shear wall model. The shaking table was actuated sequentially by four types of input gain, that is, from random gain 1 to random gain 4 with increasing scenario. The maximum displacement of experimental model on its roof top was measured for both full and no shear wall cases for four random gains. Full shear wall case showed much less displacement for all random gains compared to the no shear wall case.

The average displacement reduction ratio for four random gains is $64.4 \%$, which shows the significant effect of shear wall in lateral load resisting capability. The natural vibration frequency of full shear wall is $11.28 \mathrm{~Hz}$ compared to $5.5 \mathrm{~Hz}$ for no shear wall, which shows stiffness is about 4 times larger in the former. In the coming paper, we are going to study the natural vibration period and other dynamic characteristics of long-span Hanok.

\section{ACKNOWLEDGEMENTS}

This work was supported by a grant (21AUDP-B128638-05) from Urban and Architecture Research Program funded by Ministry of Land, Infrastructure and Transport Affairs of Korean Government. 


\section{REFERENCES}

[1] J.M. Seo, I.K. Choi, J.R. Lee, Static and Cyclic Behavior of Wooden Frames with Tenon Joints Under Lateral Load, Journal of Structural Engineering, Vol. 125, No. 3, 344349, 1999.

[2] J.S. Han, C.J. Kim, An Experimental Study on Mechanical Performance of Tenon for Analysis of Structural System and Modernization of Traditional Wooden Architecture, Journal of the Architectural Institute of Korea: Planning \& Design, Vol. 21, No. 4, 121 $128,2005$.

[3] M. Kang, N. Yang, Q. Cha, Studies on Static Performance of Mortise and Tenon Joint in Traditional Column and Tie Construction Timber Structure, Electric Technology and Civil Engineering (ICETCE), 2011 International Conference, 6197-6200, 2001.

[4] Y.W. Lee, B.S. Bae, S.G. Hong, J.G. Hwang, N.H. Kim, S.J. Jung, An Analytical Modelling of the Beam-Direction Frame of Traditional Wood Structure System, Journal of the Architectural Institute of Korea : Structure \& Construction, Vol. 22, No. 3, 29-36, 2006.

[5] Y.W. Lee, S.G. Hong, J.G. Hwang, B.S. Bae, Capacity of Lateral Load Resistance of Dori-Directional Frame with Jangbu-connection in Traditional Wood Structure System, Journal of the Architectural Institute of Korea : Structure \& Construction, Vol. 23, No. 2, 35-42, 2007.

[6] Y.M. Kim, S.G. Lee, Evaluation of Connection Stiffness of Test-bed Hanok Using a 1/4 Scale Two-Storied Model, Journal of the Architectural Institute of Korea: Structure \& Construction, Vol. 29, No. 12, 73-80, 2013.

[7] D.P. Fang, S. Iwasaki, M.H. Yu, Q.P. Shen, Y. Miyamoto, H. Hikosaka, Ancient Chinese Timber Architecture $\amalg$ : Dynamic Characteristics, Journal of Structural Engineering, Vol. 127, No. 11, 1358-1364, 2001.

[8] J.G. Hwang, S.G. Hong, Y.W. Lee, S.J. Jung, Natural Frequency Characteristics of Traditional Wooden Structure for Vibration Amplitude, Journal of the Architectural Institute of Korea : Structure \& Construction, Vol. 25, No. 5, 3-10, 2009.

[9] S.G. Lee, Y.M. Kim, J.E. Roh, S.H. Lee, S.S. Woo, Dynamic Characteristics of Traditional and New Korean-style Houses According to Excitation Amplitude. Journal of the Architectural Institute of Korea : Structure \& Construction, Vol. 29, No. 1, 49-58, 2013.

[10] A.E. Ozsoy, H. Ozkaynak, Structural and Earthquake Engineering Applications of a Model Wooden Structure. Civil Engineering and Architecture, Vol. 5, No. 1, 18-25, 2017.

[11] Y.M. Kim, J.H. Kim, A Study on the Development of Section Tables for Lateral Members of Hanok. Journal of the Architectural Institute of Korea: Structure \& Construction, Vol. 30, No. 2, 37-44, 2014.

[12] Y.M. Kim, Structural Check Schemes for the Initial Design of Columns of Hanok for Vertical Loads. Journal of the Architectural Institute of Korea: Structure \& Construction, Vol. 31, No. 11, 21-28, 2015. 
[13] Y.M. Kim, Development of Automated Structural Design Tool for Horizontal Members of Hanok, Journal of the Architectural Institute of Korea: Structure \& Construction Section, Vol. 33, No. 4, 21-28, 2017.

[14] Y.M. Kim, Development of Structural Design Tool of Hanok Columns Considering Rotational Stiffness, Journal of the Architectural Institute of Korea: Structure \& Construction Section, Vol. 33, No. 8, 29-36, 2017.

[15] Y.M. Kim, An Evaluation Scheme of Torsional Irregularity for Seismic Design of Hanok, Journal of the Architectural Institute of Korea: Structure \& Construction Section, Vol. 35, No. 10, 191-198, 2019 